\title{
Mathematical modeling of non-Newtonian fluid in arterial blood flow through various stenoses
}

\author{
Pinyo Owasit ${ }^{1,3}$ and Somchai Sriyab $2,3^{*}$ [D
}

"Correspondence:

somchai.sriyab@gmail.com

${ }^{2}$ Department of Mathematics,

Faculty of Science, Chiang Mai

University, Chiang Mai, Thailand

${ }^{3}$ Research Center in Mathematics

and Applied Mathematics,

Department of Mathematics,

Faculty of Science, Chiang Mai University, 50200, Chiang Mai,

Thailand

Full list of author information is

available at the end of the article

\begin{abstract}
Since the stenosis geometry of some cardiovascular patients cannot be described by a vertically symmetric function throughout the stenosis, so it motivates us to study the blood flow through a vertically asymmetric stenosis. In addition, we compare the flow quantities in bothvertically symmetric and asymmetric stenoses. The vertically symmetric stenosis is explained by a vertically symmetric function such as an exponential function in bell shape and a cosine function in cosine shape. The vertically asymmetric stenosis is interpreted by a vertically asymmetric function such as the combination of two different stenosis shapes. Blood is treated as a non-Newtonian fluid which is represented in the power-law model. The finite difference scheme is used to solve governing equations for obtaining the flow quantities such as axial velocity, radial velocity, flow rate, resistance to flow, and skin friction. We investigated the way that the stenosis height, stenosis length, and non-Newtonian behavior affect the flow quantities through three various stenoses. The flow quantities in the bell shape and cosine shape of stenosis show significantly different behavior. Moreover, we found that the flow quantities in the single shape (bell shape or cosine shape) have the same behavior as the flow quantities in the combined shape in the first half part, but have a slightly different behavior in the last half part.
\end{abstract}

MSC: 92B05; $76 Z 05$

Keywords: Cardiovascular disease; Non-Newtonian fluid; Power-law model; Stenosed geometry and flow quantities

\section{Introduction}

Arterial stenosis is the major cause of many cardiovascular diseases such as myocardial infarction and cerebral stroke. Thus, the study of blood flow through the stenosed artery is necessary. Some researchers treat blood as Newtonian fluid [1, 2]. The Newtonian behavior not only describes blood flow in a large radius of the artery but also explains the gas transportation in the atmosphere [3]. However, Z. Ismail and his co-workers suggest that non-Newtonian behavior is an important factor [4]. Their investigation shows that blood becomes non-Newtonian when the radius of an artery is smaller than one $\mathrm{mm}$. There

(c) The Author(s) 2021. This article is licensed under a Creative Commons Attribution 4.0 International License, which permits use sharing, adaptation, distribution and reproduction in any medium or format, as long as you give appropriate credit to the original author(s) and the source, provide a link to the Creative Commons licence, and indicate if changes were made. The images or other third party material in this article are included in the article's Creative Commons licence, unless indicated otherwise in a credit line to the material. If material is not included in the article's Creative Commons licence and your intended use is not permitted by statutory regulation or exceeds the permitted use, you will need to obtain permission directly from the copyright holder. To view a copy of this licence, visit http://creativecommons.org/licenses/by/4.0/. 
are various non-Newtonian models that are widely applied in representing blood flow behavior. The non-Newtonian models that are frequently used are power-law [4-7], Casson [8-10], and the Herschel-Bulkley model [11]. The power-law and Herschel-Bulkley models have more advantages than the Casson model, and the power index can be adjusted to a desired value, while the Casson model has a fixed power index. The yield stress affects the Herschel-Bulkley and Casson models but is not considered in the power-law model. However, P. Easthope and D. Brooks found that power-law is highly effective in modeling the blood flow [12].

The geometry of stenosis may be complicated as it is based on each individual patient. Different types of stenosis models have been studied. We can classify the model into three groups based on mathematical expressions such as the exponential shape or bell shape stenosis, cosine shape, and polynomial shape. S. Nadeem and his co-workers [6], P. K. Mandel [7], S. Chakravarty and P. K. Mandel [2], added the taper effect to the stenosis. Moreover, S. Nadeem and his co-workers studied microvascular blood flow with heat transfer in complex wavy channel [13]. Z. Ismail and his co-workers [4] considered overlapping stenosis and N. Mustapha and her co-workers studied multi-stenosis shapes [1]. Moreover, Y. Bin Tan and N. Mustapha added the gravity effect in stenosed artery [14, 15]

From the above literature reviews, the researchers studied only the blood flow through a vertically symmetric stenosis. In our work, we study the two-dimensional steady flow of the power-law fluid through vertically symmetric and asymmetric stenoses. The vertically symmetric stenosis is classified in two types such as bell shape and cosine shape. The vertically asymmetric stenosis is the combined shape between bell shape and cosine shape that the first half part is bell shape or cosine shape, but the last half part is a different one. We applied the finite difference method to solve the governing equation, and important flow quantities were obtained such as axial velocity, radial velocity, flow rate, resistance to flow, and skin friction. Moreover, the effect of the stenosis depth, length, and non-Newtonian behavior inflow quantities was investigated.

\section{Stenosis model}

The stenotic models in our study are classified into four different shapes such as the bell shape, the cosine shape, the combination of bell and cosine shape, and the combination of cosine and bell shape. The vertically symmetric stenosis is explained by a vertically symmetric function throughout entire stenosis geometry, namely an exponential function in bell shape and a cosine function in cosine shape. The vertically asymmetric stenosis is described by a vertically asymmetric function such as the combination of two different stenosis shapes. The combination of bell and cosine shapes means that the first half part is bell shape, but the last half part is cosine shape. The combination of cosine and bell shape means that the cosine and bell shapes are located in the first half part and the second half part, respectively. The geometries of a stenosed artery are shown in Fig. 1. Since the stenosis geometry of some cardiovascular patients cannot be described by a vertically symmetric stenosis, we propose to study the blood flow through a vertically asymmetric stenosis, for example, the combination of two different stenosis geometries.

The equations that describe the geometry of the stenosis models in the bell shape and cosine shape are as expressed in Eq. (1) and Eq. (2), respectively [10, 16].

$$
R(z)=-R_{0}\left(1-a e^{-b(z-L)^{2}}\right),
$$




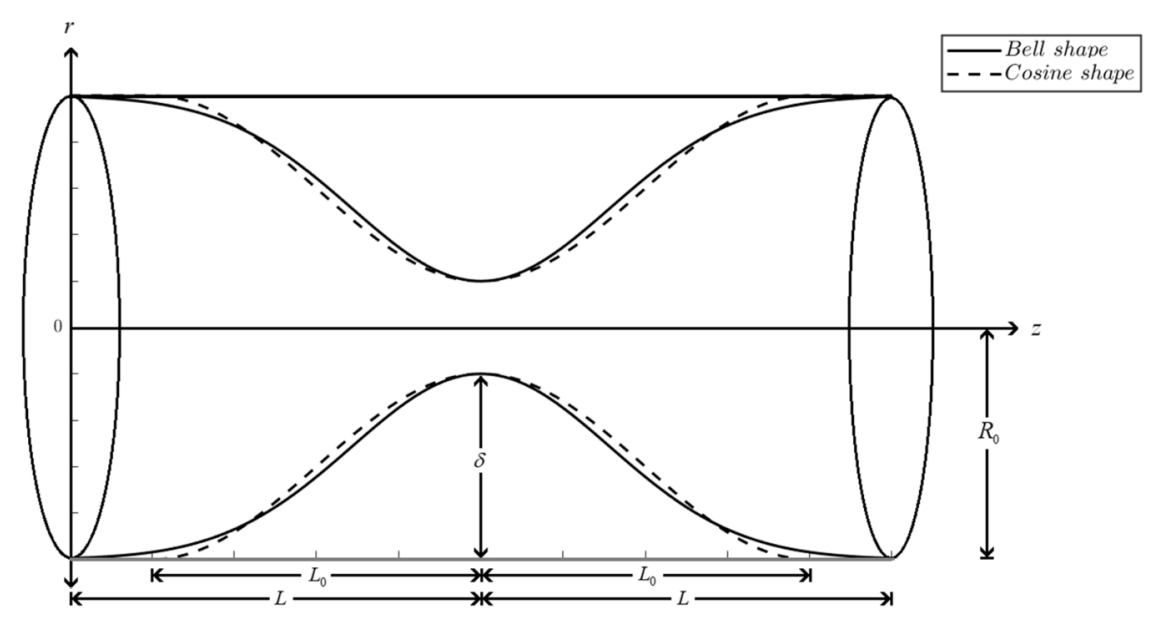

Figure 1 Geometry of stenosed artery with bell shape and cosine shape

where $a=\frac{\delta}{R_{0}}$ and $b=\left(\frac{m}{L_{0}}\right)^{2}$,

$$
R(z)=-R_{0}+\frac{\delta}{2}\left[1+\cos \frac{\pi(z-L)}{L_{0}}\right]
$$

There are common parameters in both models such as $R_{0}, R(z), L_{0}$, and $L$, where $R_{0}$ is the radius of a normal artery, $R(z)$ is the radius of a stenosed artery, $\delta$ is the highest depth of the stenosis, $L$ is the half-length of an artery, and $L_{0}$ is the half-length of the stenosis.

For bell-shaped stenosis, $a$ and $b$ are the dimensionless parameters, where $a$ is the ratio of stenosed depth and the radius of a normal artery, $b$ is the square of the ratio of constant value $m$ and the half-length of the stenosis.

\section{Mathematical analysis}

\subsection{Governing equations}

The study of the stenotic blood flow in an arterial segment is considered to be laminar, steady, two-dimensional, axisymmetric, and fully developed, and the flowing blood is treated to be an incompressible, power-law fluid. The non-Newtonian behavior will be established to study the blood flow through the stenosis when the shear rate is less than $100 \mathrm{~s}^{-1}$. Under these assumptions, the governing equations can be written in the cylindrical coordinates system $(r, \theta, z)$ as follows.

Equation of continuity

$$
\frac{\partial v_{r}}{\partial r}+\frac{v_{r}}{r}+\frac{\partial v_{z}}{\partial z}=0 .
$$

Equation of momentum

$$
\begin{aligned}
& v_{r} \frac{\partial v_{z}}{\partial r}+v_{z} \frac{\partial v_{z}}{\partial z}=-\frac{1}{\rho} \frac{\partial p}{\partial z}-\frac{1}{\rho}\left[\frac{1}{r} \frac{\partial\left(r \tau_{r z}\right)}{\partial r}+\frac{\partial \tau_{z z}}{\partial z}\right] \\
& v_{r} \frac{\partial v_{r}}{\partial r}+v_{z} \frac{\partial v_{r}}{\partial z}=-\frac{1}{\rho} \frac{\partial p}{\partial r}-\frac{1}{\rho}\left[\frac{1}{r} \frac{\partial\left(r \tau_{r r}\right)}{\partial r}+\frac{\partial \tau_{r z}}{\partial z}\right] .
\end{aligned}
$$


Here, $\tau_{r z}, \tau_{r r}$, and $\tau_{z z}$ are shear stress of the power-law model respectively as defined in $[4,17], v_{z}$ is the axial velocity, $v_{r}$ is the radial velocity, $\rho$ is the density of the fluid, and $p$ is the pressure of the fluid.

$$
\begin{aligned}
& \tau_{r z}=-k \gamma^{\cdot n-1}\left(\frac{\partial v_{r}}{\partial z}+\frac{\partial v_{z}}{\partial r}\right), \\
& \tau_{z z}=-2 k \gamma^{\cdot n-1}\left(\frac{\partial v_{z}}{\partial z}\right) \\
& \tau_{r r}=-2 k \gamma^{\cdot n-1}\left(\frac{\partial v_{r}}{\partial r}\right)
\end{aligned}
$$

where $\gamma^{\prime}=\sqrt{2\left[\left(\frac{\partial v_{r}}{\partial r}\right)^{2}+\left(\frac{v_{r}}{r}\right)^{2}+\left(\frac{\partial v_{z}}{\partial z}\right)^{2}\right]+\left(\frac{\partial v_{r}}{\partial z}+\frac{\partial v_{z}}{\partial r}\right)^{2}}$, and $k$ is the flow consistency index.

Boundary condition. There is no radial flow along the axis of the artery. The axial velocity gradient is assumed to be zero, which means there is no shear rate of fluid along the axis. On the arterial wall, axial velocity and radial velocity are assumed to be zero. The boundary conditions can be expressed as:

$$
\begin{aligned}
& v_{r}(r, z)=0, \quad \frac{\partial v_{z}}{\partial r}(r, z)=0, \quad \tau_{r z}=0, \quad \text { on } r=0, \\
& v_{r}(r, z)=0, \quad v_{z}(r, z)=0, \quad \text { on } r=R(z) .
\end{aligned}
$$

\subsection{Transformation of governing equations}

In order to immobilize the arterial wall $[2,4,7]$, we used the radial coordinate transformation $y=\frac{r}{R(z)}$. Then Eq. (3)-(5) and Eq. (6)-(7) may be written as follows:

$$
\begin{aligned}
& \frac{1}{R} \frac{\partial v_{r}}{\partial y}+\frac{v_{r}}{y R}+\frac{\partial v_{z}}{\partial z}-\frac{y}{R} \frac{d R}{d z} \frac{\partial v_{z}}{\partial y}=0 \\
& {\left[-\frac{v_{r}}{R}+v_{z} \frac{y}{R} \frac{d R}{d z}\right] \frac{\partial v_{z}}{\partial y}-v_{z} \frac{\partial v_{z}}{\partial z}-\frac{1}{\rho} \frac{\partial p}{\partial z}-\frac{1}{\rho}\left[\frac{\tau_{y z}}{y R}+\frac{1}{R} \frac{\partial \tau_{y z}}{\partial y}+\frac{\partial \tau_{z z}}{\partial z}-\frac{y}{R} \frac{d R}{d z} \frac{\partial \tau_{y z}}{\partial y}\right]=0} \\
& \tau_{y z}=-k \gamma^{\cdot n-1}\left(\frac{\partial v_{r}}{\partial z}-\frac{y}{R} \frac{d R}{d z} \frac{\partial v_{r}}{\partial y}+\frac{1}{R} \frac{\partial v_{z}}{\partial y}\right) \\
& \tau_{z z}=-2 k \gamma^{\cdot n-1}\left(\frac{\partial v_{z}}{\partial z}-\frac{y}{R} \frac{d R}{d z} \frac{\partial v_{z}}{\partial y}\right)
\end{aligned}
$$

where

$$
\gamma^{\cdot}=\sqrt{2\left[\left(\frac{1}{R} \frac{\partial v_{r}}{\partial y}\right)^{2}+\left(\frac{v_{r}}{y R}\right)^{2}+\left(\frac{\partial v_{z}}{\partial z}-\frac{y}{R} \frac{d R}{d z} \frac{\partial v_{z}}{\partial y}\right)^{2}\right]+\left(\frac{\partial v_{r}}{\partial z}-\frac{y}{R} \frac{d R}{d z} \frac{\partial v_{r}}{\partial y}+\frac{1}{R} \frac{\partial v_{z}}{\partial y}\right)^{2}} .
$$

The transformation boundary and initial conditions are:

$$
\begin{aligned}
& v_{r}(y, z)=0, \quad \frac{\partial v_{z}}{\partial y}(y, z)=0, \quad \tau_{y z}=0, \quad \text { on } y=0, \\
& v_{r}(y, z)=0, \quad v_{z}(y, z)=0, \quad \text { on } y=1 .
\end{aligned}
$$




\subsection{Method of solution}

We obtain the radial velocity by the multiplication of $y R$ in Eq. (11) and then integrate this with respect to $y$ from 0 to 1 , and we get

$$
\left[v_{r}\right]_{0}^{1}=\left[y \frac{d R}{d z} v_{z}\right]_{0}^{1}-\frac{R}{y} \int_{0}^{1} y \frac{\partial v_{z}}{\partial z} d y-\frac{2}{y} \frac{d R}{d z} \int_{0}^{1} y v_{z} d y .
$$

Using boundary condition (16), Eq. (18) takes the following form:

$$
\int_{0}^{1} y \frac{\partial v_{z}}{\partial z} d y=-\frac{2}{R} \frac{d R}{d z} \int_{0}^{1} y v_{z} d y
$$

Since $R=R(z)$, Eq. (19) can be written as follows:

$$
\int_{0}^{1} y \frac{\partial v_{z}}{\partial z} d y=-\int_{0}^{1} y \frac{2}{R} \frac{d R}{d z} v_{z} d y
$$

Comparing both sides of the equation, we have

$$
\frac{\partial v_{z}}{\partial z}=-\frac{2}{R} \frac{d R}{d z} v_{z}
$$

Substituting Eq. (21) into Eq. (11) and multiplying by $y R$, we obtain

$$
y \frac{\partial v_{r}}{\partial y}+v_{r}=2 y \frac{d R}{d z} v_{z}+y^{2} \frac{d R}{d z} \frac{\partial v_{z}}{\partial y} .
$$

Equation (22) can be rewritten as follows:

$$
\frac{\partial}{\partial y}\left(y v_{r}\right)=\frac{\partial}{\partial y}\left(y^{2} \frac{d R}{d z} v_{z}\right) .
$$

Finally, the radial velocity is obtained

$$
v_{r}=y \frac{d R}{d z} v_{z}
$$

In order to obtain $v_{r}$, we plug $v_{r}$ into Eq. (12), and the equations of axial momentum are reduced to

$$
-v_{z} \frac{\partial v_{z}}{\partial z}-\frac{1}{\rho} \frac{\partial p}{\partial z}-\frac{1}{\rho}\left[\frac{\tau_{y z}}{y R}+\frac{1}{R} \frac{\partial \tau_{y z}}{\partial y}+\frac{\partial \tau_{z z}}{\partial z}-\frac{y}{R} \frac{d R}{d z} \frac{\partial \tau_{y z}}{\partial y}\right]=0 .
$$

The volumetric flow rate $(Q)$ is given by the following equation:

$$
Q=\int_{0}^{R} \int_{0}^{2 \pi} v_{z} r d \theta d r=2 \pi \int_{0}^{R} v_{r} r d r .
$$

By using the radial coordinate transformation, $r=y R$, we get

$$
Q=2 \pi R^{2} \int_{0}^{1} v_{z} y d y .
$$




\section{Numerical procedure}

The discretization of $v_{z}(y, z), v_{r}(y, z), \tau_{y z}(y, z)$, and $\tau_{y z}(y, z)$ is written as $v_{z}\left(y_{i}, z_{j}\right), v_{r}\left(y_{i}, z_{j}\right)$, $\tau_{y z}\left(y_{i}, z_{j}\right)$, and $\tau_{y z}\left(y_{i}, z_{j}\right)$. Here we define $y_{i}=-1+(i-1) \Delta y, i=1,2, \ldots, N+1$, where $\Delta y=\frac{1}{N}$, $-1 \leq y \leq 0 . z_{j}=(j-1) \Delta z j=1,2, \ldots, M+1$, where $\Delta z=\frac{2 L}{M}, 0 \leq z \leq 2 L$.

The finite difference scheme is applied to solve Eq. (25). $\frac{\partial v_{z}}{\partial y}, \frac{\partial v_{r}}{\partial y}, \frac{\partial v_{r}}{\partial z}$, and $\frac{\partial v_{z}}{\partial z}$ are approximated based on forward difference as shown below:

$$
\begin{aligned}
& \left(\frac{\partial v_{z}}{\partial y}\right)_{i, j}=\frac{\left(v_{z}\right)_{i+1, j}-\left(v_{z}\right)_{i, j}}{\Delta y}, \\
& \left(\frac{\partial v_{z}}{\partial z}\right)_{i, j}=\frac{\left(v_{z}\right)_{i, j+1}-\left(v_{z}\right)_{i, j}}{\Delta z}, \\
& \left(\frac{\partial v_{r}}{\partial y}\right)_{i, j}=\frac{\left(v_{r}\right)_{i+1, j}-\left(v_{r}\right)_{i, j}}{\Delta y}, \\
& \left(\frac{\partial v_{r}}{\partial z}\right)_{i, j}=\frac{\left(v_{r}\right)_{i, j+1}-\left(v_{r}\right)_{i, j}}{\Delta z} .
\end{aligned}
$$

However, $\frac{\partial v_{z}}{\partial z}$ will be obtained by discretizing Eq. (21).

$$
\left(\frac{\partial v_{z}}{\partial z}\right)_{i, j}=-\frac{2}{R_{j}}\left(\frac{d R}{d z}\right)_{j}\left(v_{z}\right)_{i, j}
$$

We can find $\left(v_{z}\right)_{i, j+1}$ by plugging Eq. (31) into Eq. (28), and we obtain

$$
\left(v_{z}\right)_{i, j+1}=\left[1-\frac{2 \Delta z}{R_{j}}\left(\frac{d R}{d z}\right)_{j}\right]\left(v_{z}\right)_{i, j} .
$$

The derivatives of $\tau_{y z}$ and $\tau_{z z}$ are discretized by the forward differences also.

$$
\begin{aligned}
& \left(\frac{\partial \tau_{y z}}{\partial y}\right)_{i, j}=\frac{\left(\tau_{y z}\right)_{i+1, j}-\left(\tau_{y z}\right)_{i, j}}{\Delta y}, \\
& \left(\frac{\partial \tau_{y z}}{\partial z}\right)_{i, j}=\frac{\left(\tau_{y z}\right)_{i, j+1}-\left(\tau_{y z}\right)_{i, j}}{\Delta z}, \\
& \left(\frac{\partial \tau_{z z}}{\partial y}\right)_{i, j}=\frac{\left(\tau_{z z}\right)_{i+1, j}-\left(\tau_{z z}\right)_{i, j}}{\Delta y}, \\
& \left(\frac{\partial \tau_{z z}}{\partial z}\right)_{i, j}=\frac{\left(\tau_{z z}\right)_{i, j+1}-\left(\tau_{z z}\right)_{i, j}}{\Delta z} .
\end{aligned}
$$

Using Eq. (27)-(36), the discretization of Eq. (25), (13), (14), and (15) can be written as follows:

$$
\begin{aligned}
& -\left(v_{z}\right)_{i, j}\left(\frac{\partial v_{z}}{\partial z}\right)_{i, j}-\frac{\Delta p}{2 L \cdot \rho} \\
& -\frac{1}{\rho}\left[\frac{\left(\tau_{y z}\right)_{i, j}}{y_{i} R_{j}}+\frac{1}{R_{j}}\left(\frac{\partial \tau_{y z}}{\partial y}\right)_{i, j}+\left(\frac{\partial \tau_{z z}}{\partial z}\right)_{i, j}-\frac{y_{i}}{R_{j}}\left(\frac{d R}{d z}\right)_{j}\left(\frac{\partial \tau_{y z}}{\partial y}\right)_{i, j}\right]=0, \\
& \left(\tau_{y z}\right)_{i, j}=-k \gamma_{i, j}^{n-1}\left[\left(\frac{\partial v_{r}}{\partial z}\right)_{i, j}-\frac{y_{i}}{R_{j}}\left(\frac{d R}{d z}\right)_{j}\left(\frac{\partial v_{r}}{\partial y}\right)_{i, j}+\frac{1}{R_{j}}\left(\frac{\partial v_{z}}{\partial y}\right)_{i, j}\right],
\end{aligned}
$$


Table 1 The value of the parameter ranges

\begin{tabular}{ll}
\hline Parameter & Values \\
\hline$L$ & $8-10 \mathrm{~cm}$ \\
$L_{0}$ & $3-8 \mathrm{~cm}$ \\
$R_{0}$ & $0.1 \mathrm{~cm}$ \\
$\delta$ & $0.03-0.08 \mathrm{~cm}$ \\
$m$ & $1.4-1.8$ \\
$\rho$ & $1.06 \mathrm{~g} / \mathrm{cm}^{3}$ \\
$-\Delta p / 2 L$ & $50 \mathrm{~g} / \mathrm{cm}^{2} \mathrm{~s}^{2}$ \\
$k$ & 0.02 \\
$n$ & $0.61-1$ \\
\hline
\end{tabular}

$$
\begin{aligned}
& \left(\tau_{z z}\right)_{i, j}=-2 k \gamma_{i, j}^{\cdot n-1}\left[\left(\frac{\partial v_{r}}{\partial z}\right)_{i, j}-\frac{y_{i}}{R_{j}}\left(\frac{d R}{d z}\right)_{j}\left(\frac{\partial v_{z}}{\partial y}\right)_{i, j}\right], \\
& \dot{\gamma}_{i, j}=\sqrt{\begin{array}{l}
2\left\{\left[\frac{1}{R_{j}}\left(\frac{\partial v_{r}}{\partial y}\right)_{i, j}\right]^{2}+\left[\frac{\left(v_{r}\right)_{i, j}}{y_{i} R_{j}}\right]^{2}+\left[\left(\frac{\partial v_{z}}{\partial z}\right)_{i, j}-\frac{y_{i}}{R_{j}}\left(\frac{d R}{d z}\right)_{j}\left(\frac{\partial v_{z}}{\partial y}\right)_{i, j}\right]^{2}\right\} \\
+\left[\left(\frac{\partial v_{r}}{\partial z}\right)_{i, j}-\frac{y_{i}}{R_{j}}\left(\frac{d R}{d z}\right)_{j}\left(\frac{\partial v_{r}}{\partial y}\right)_{i, j}+\frac{1}{R_{i}}\left(\frac{\partial v_{z}}{\partial y}\right)_{i, j}\right]^{2}
\end{array}},
\end{aligned}
$$

The boundary conditions are discretized as follows:

$$
\begin{aligned}
& \left(v_{r}\right)_{N+1, j}=0, \quad\left(v_{z}\right)_{N, j}=\left(v_{z}\right)_{N+1, j}, \quad\left(\tau_{y z}\right)_{N+1, j}=0 . \\
& \left(v_{r}\right)_{1, j}=0, \quad\left(v_{z}\right)_{1, j}=0 .
\end{aligned}
$$

The axial velocity will be solved by using Eq. (37) - (40) with boundary conditions (41)(42). Then, the radial velocity can be solved by the discretization of Eq. (24) as follows:

$$
\left(v_{r}\right)_{i, j}=y_{i}\left(\frac{d R}{d z}\right)_{j}\left(v_{z}\right)_{i, j}
$$

While the volumetric flow rate can be approximated by discretizing Eq. (26):

$$
Q_{j}=2 \pi R_{j}^{2} \Delta y \sum_{i=1}^{N+1}\left(v_{z}\right)_{i, j} y_{i} \quad \text { for } j=1,2, \ldots, M+1
$$

The resistance to flow ( $\lambda$ ) can be obtained by using Eq. (45).

$$
\lambda_{j}=\frac{\Delta p}{Q_{j}} .
$$

\section{Numerical results}

This research provides data to study important factors such as the axial velocity, radial velocity, flow rate, and resistance to flow. The values of the parameter ranges are shown in Table 1. The parameter values correspond to reference no. [11, 12, 17, 18].

\subsection{Axial velocity}

The behavior of axial velocity flowing through various stenosis arteries is shown in Figs. 2 to 12 . The axial velocity is zero at the arterial wall $(y=-1)$ and increases along the radial axis. The highest axial velocity is located at the center of the stenotic region $(\bar{z}=0.5)$ and 
Figure 2 Variation of axial velocity with radial distance for different stenosis heights in bell shape and combined shape of bell and cosine stenosis at $\bar{z}=0.8$

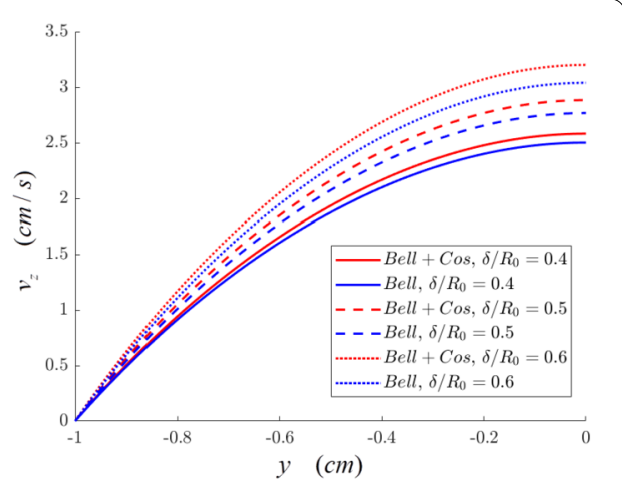

Figure 3 Variation of axial velocity with axial distance for different stenosis heights in bell shape and combined shape of bell and cosine stenosis at $y=-0.5$

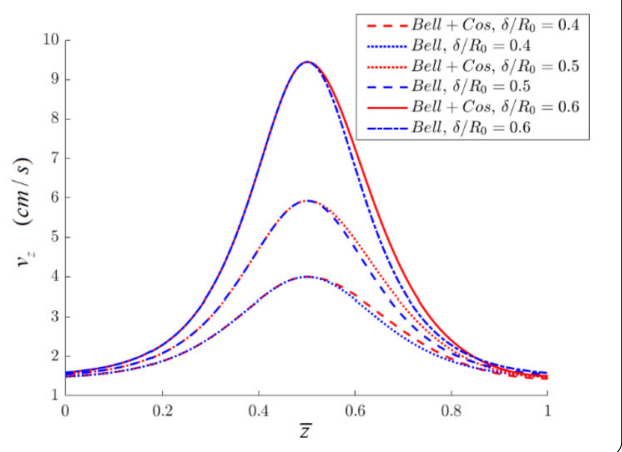

Figure 4 Variation of axial velocity with radial distance for different stenosis heights in cosine shape and combined shape of cosine and bell stenosis at $\bar{z}=0.8$

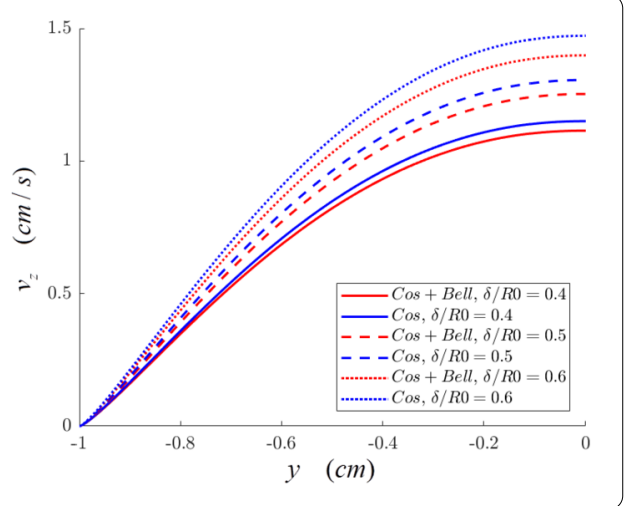

decreases exponentially in other regions along the axial axis. These results correspond to those of Mandel [7], Molla [19, 20], and Shupti [21].

The effect of the stenosis height has been investigated in Figs. 2 to 5. It is observed that the axial velocity increases considerably with the increasing stenosis height around the center of the stenosis region $(\bar{z}=0.5)$, but the effect seems less significant near the entrance and the exit of the stenotic region. This result corresponds to that of Malota [22].

The effect of the stenosis length has been studied in Figs. 6 and 7. The results are similar to the effect of stenosis height in that the axial velocity in a long stenosis length gives higher values than the axial velocity in a short stenosis. The stenosis length affects the axial velocity more near the entrance and exit of the artery than stenosis height. 
Figure 5 Variation of axial velocity with axial distance for different stenosis heights in cosine shape and combined shape of cosine and bell stenosis at $y=-0.5$
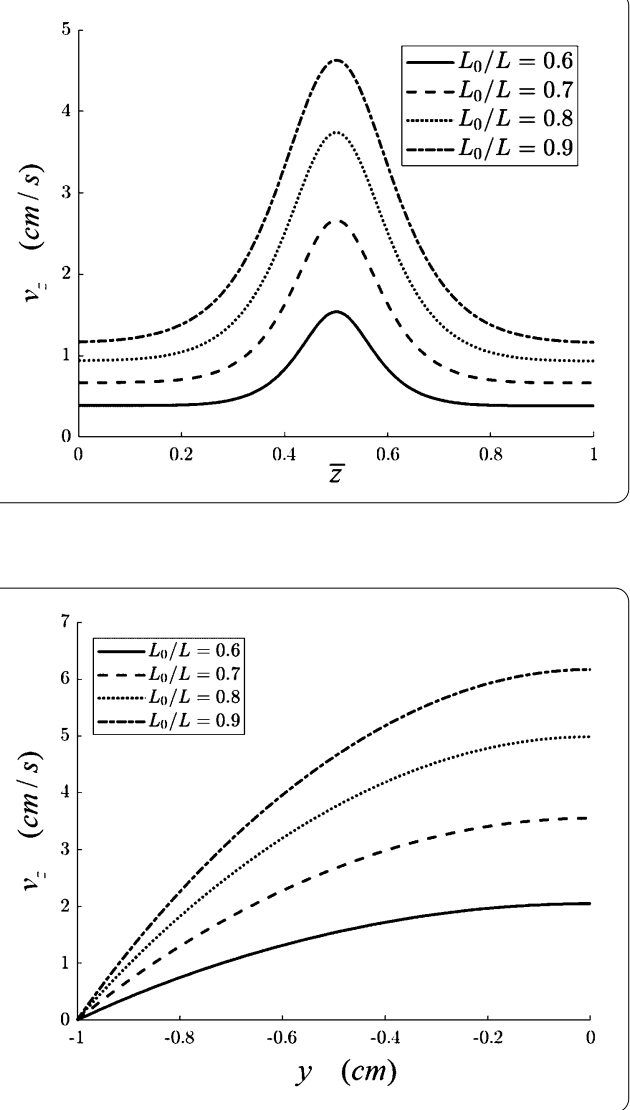

Figure 6 Variation of axial velocity with radial distance for different stenosis lengths in bell shape stenosis at $\bar{z}=0.5$

We compare the behavior of the Newtonian fluid $(n=1)$ with non-Newtonian (powerlaw fluid in Figs. 8 and 9. We can obviously see that the axial velocity is higher in the Newtonian than in the non-Newtonian model. When blood acts as a non-Newtonian fluid, the axial velocity in the combined shape of bell and cosine shape is higher than the axial velocity in the combined shape of cosine and bell shape. However, the axial velocity is higher in the combined shape of cosine and bell than in the combined shape of bell and cosine when the blood behaves as a Newtonian fluid. Figure 10 shows that the geometry of the bell shape looks like the geometry of the cosine shape when $m$ is 1.8. The axial velocity in different shapes of stenosis along the axial and radial distance is studied in Figs. 11 to 12 , respectively. It is indicated that axial velocity in the cosine shape is much lower than in the bell shape.

The comparative results of the bell shape, cosine shape, combined shape of bell and cosine, and combined shape of cosine and bell are shown in Figs. 2 to 5. From the entrance of the stenosed region to the center of the stenosed region, the bell shape, and combined shape of bell and cosine shapes give the same value of axial velocity due to the same geometry. However, from the center to the exit of the stenosed region, the axial velocity in the bell shape is slightly higher than in the combined shape of bell and cosine shapes because of the geometric difference. Axial velocity in the cosine shape and combined shape of cosine and bell shapes is equal in the first half of the stenosed region too, but the axial velocity in the cosine shape is slightly higher than in the combined shape of cosine and bell shapes in the other part of stenosis. 
Figure 7 Variation of axial velocity with axial distance for different stenosis lengths in bell shape stenosis at $y=-0.5$
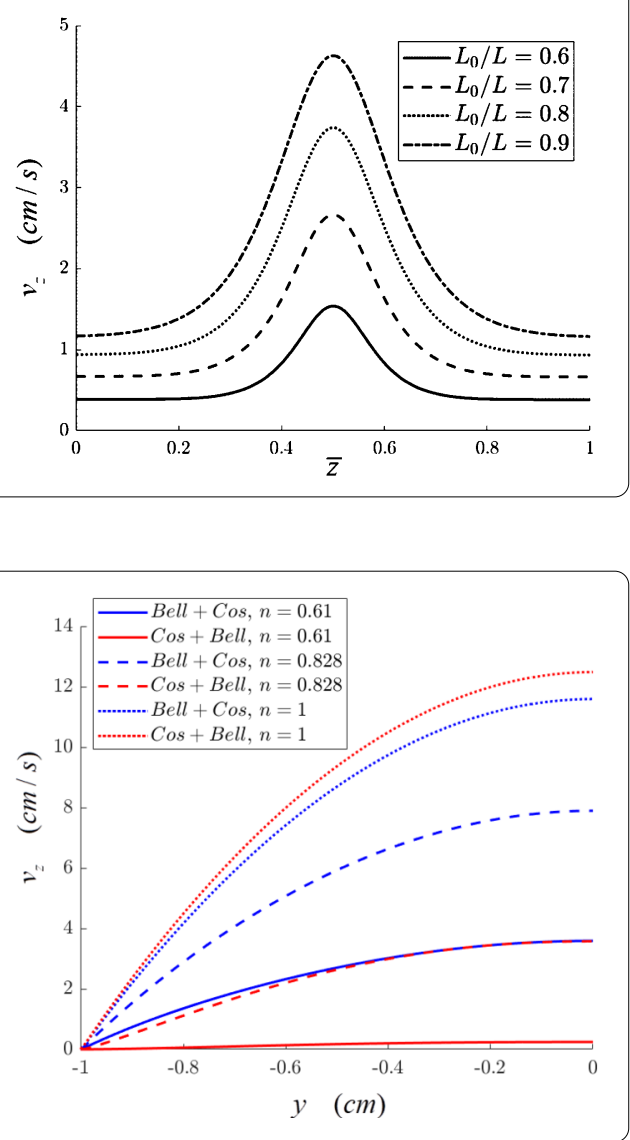

Figure 8 Variation of axial velocity with radial distance for non-Newtonian ( $n=0.61$ and $n=0.828$ ) and Newtonian fluid $(n=1)$ in combined shape of cosine and bell and combined shape of bell and cosine stenosis at $\bar{z}=0.8$

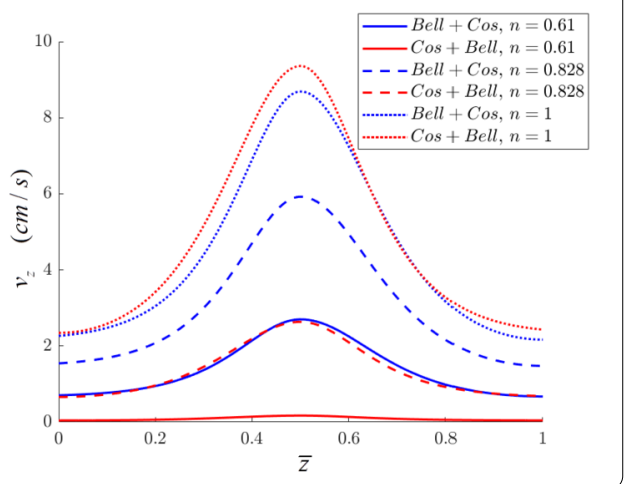

\subsection{Radial velocity}

Figures 13 to 24 show the radial velocity of blood flow through various shaped stenoses. The radial velocity gives a much lower value than the axial velocity which is in accordance with Mandel [7]. The radial velocity gives a negative value when the dimensionless axial position $(\bar{z})$ is less than 0.5 , but it gives a positive value with the same magnitude when the dimensionless axial position $(\bar{z})$ is greater than 0.5 . The radial velocity changes from a negative to positive value which indicates the change in direction of radial velocity.

The effect of stenosis height and stenosis length on radial velocity is similar to axial velocity. When stenosis height and stenosis length increase, the magnitude of radial velocity 
Figure 10 Geometry of stenosis artery of bell shape with different $m$ and cosine shape where $\delta / R_{0}=0.8$ and $L_{0} / L=1$

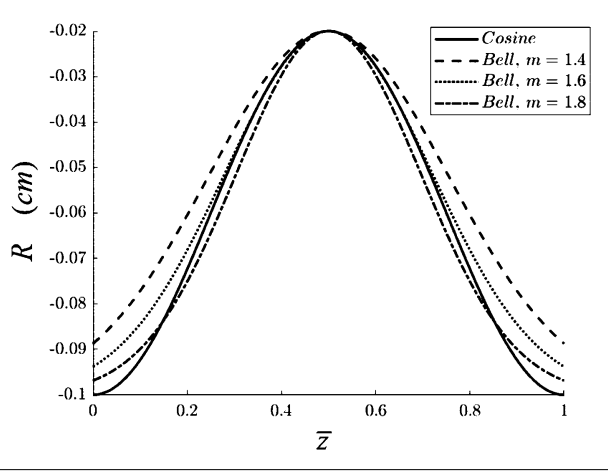

Figure 11 The comparison between bell shape with different $m$ and cosine shape of axial velocity along radial axis at $\bar{z}=0.5$

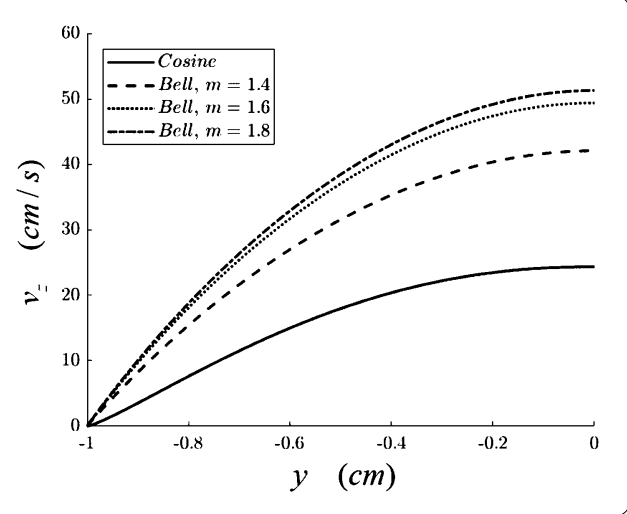

Figure 12 The comparison between bell shape with different $m$ and cosine shape of axial velocity along axial axis at $y=-0.5$

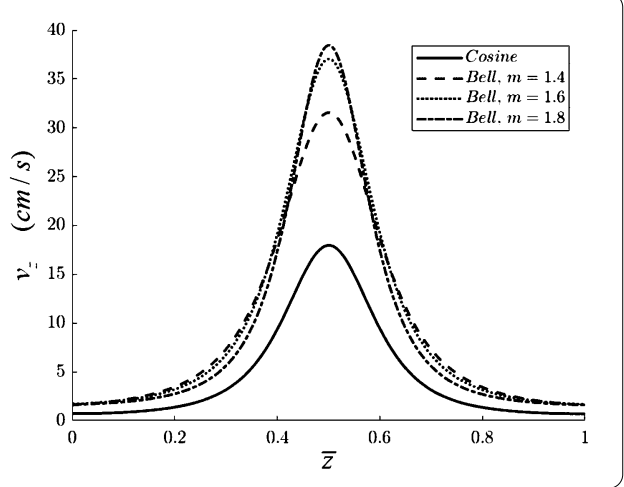

increases too. The magnitude of the radial velocity of Newtonian fluid is higher than the power-law fluid according to axial velocity. The radial velocity in the bell and cosine shapes is observed in Figs. 23 and 24. This clearly indicates that radial velocity in the cosine shape is lower than that of the bell shape.

The effect of the combined shape in radial velocity is in accordance with axial velocity as shown in Figs. 13 to 16 and Figs. 19 to 22 . When $\bar{z} \leq 0.5$, the radial velocity in the cosine shape is equivalent to the radial velocity in the combined shape of cosine and bell shapes, and the radial velocity in the bell shape is also equivalent to the radial velocity in the combined shape of bell and cosine shapes. When $\bar{z}>0.5$, the radial velocities of the combined shapes and the radial velocities of a single shape are slightly different. 
Figure 13 Variation of radial velocity with radial distance for different stenosis heights in bell shape and combined shape of bell and cosine stenosis at $\bar{z}=0.8$

Figure 14 Variation of radial velocity with axial distance for different stenosis heights in bell shape and combined shape of bell and cosine stenosis at $y=-0.5$ distance for different stenosis heights in cosine shape and combined shape of cosine and bell stenosis at $\bar{z}=0.8$
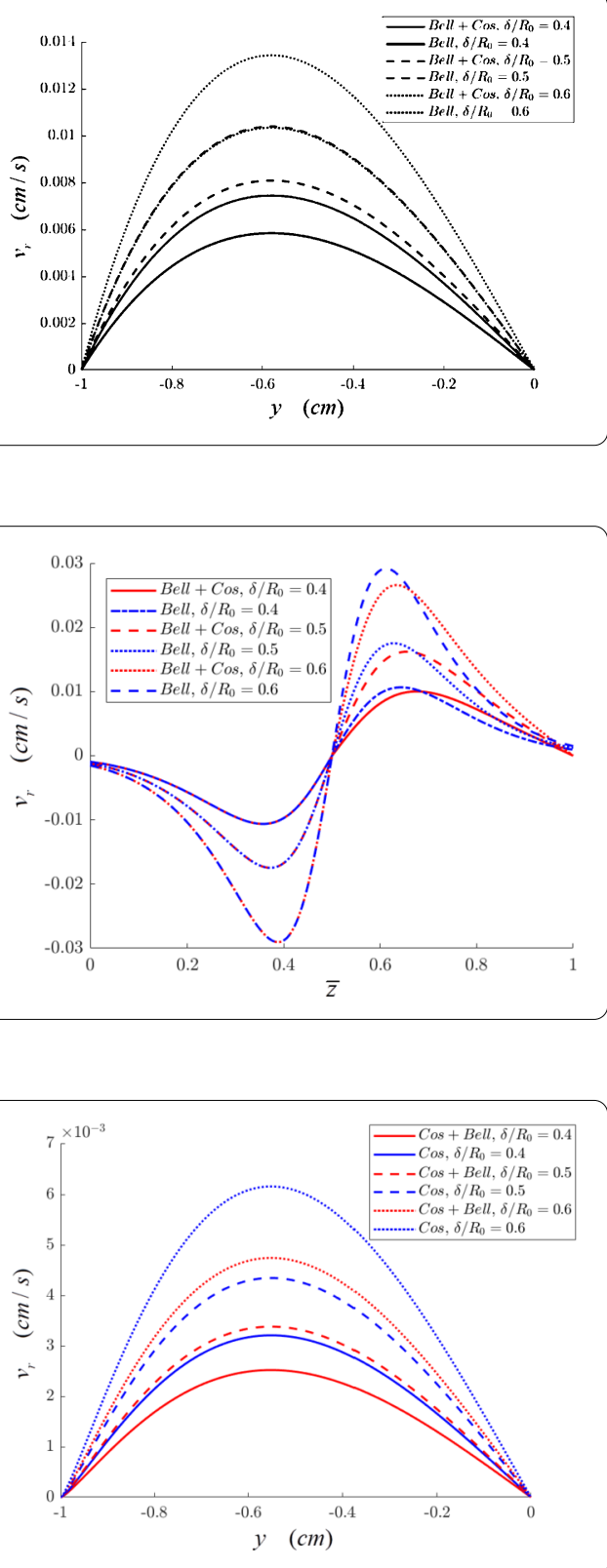

\subsection{Flow rate and resistance to flow}

Figures 25 to 27 show that when $\bar{z}<0.4$, the flow rate in the single and combined shape exhibits a downward trend, and when $0.4<\bar{z}<0.6$, the flow rate is an upward trend, and when $0.6<\bar{z}<1$, the rate is downward again. Whereas the flow rate from Venkatsan's [9] and Sriyab's study [10] shows a downward trend when $\bar{z}<0.5$ and an upward trend when $\bar{z}>0.5$. The effect of the stenosis height shown in Figs. 25 and 26 is in accordance with the axial and radial velocity where flow rate increases with the increase of stenosis height in the bell shape and combined shape of bell and cosine shape. However, the flow rate decreases with the increase of stenosis height in the cosine shape and combined shape of cosine and bell shape. In Fig. 27, the flow rate in the cosine shape is considerably lower than that in the bell shape. The flow rate increases suddenly when the value of $m$ increases. 
Figure 16 Variation of radial velocity with axial shape and combined shape of cosine and bell stenosis at $y=-0.5$ distance for different stenosis heights in cosine
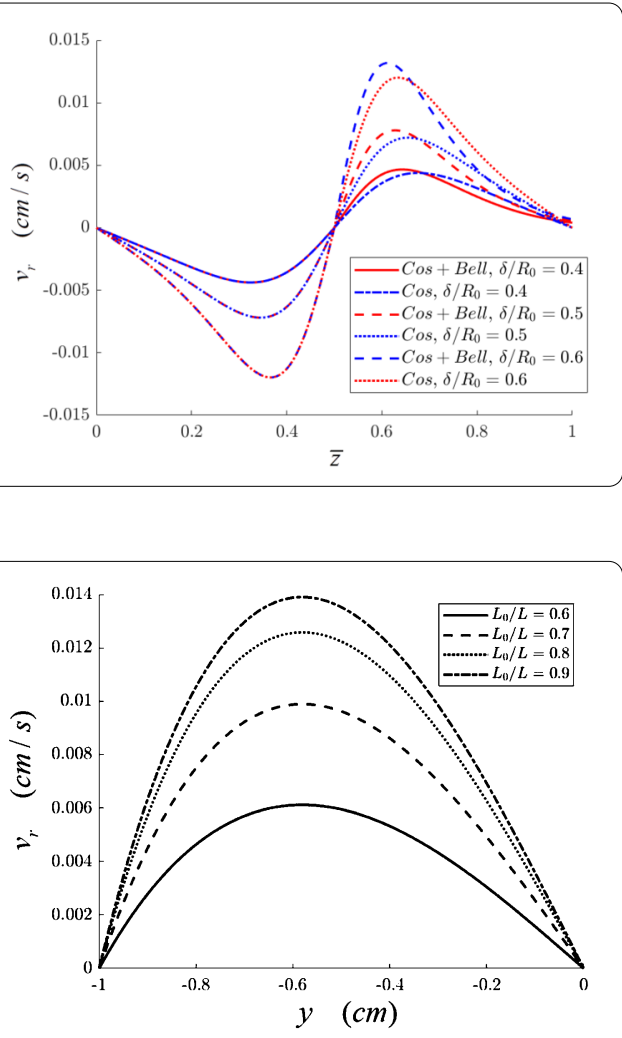

Figure 17 Variation of radial velocity with radial distance for different stenosis lengths in bell shape stenosis at $\bar{z}=0.6$

Figure 18 Variation of radial velocity with axial distance for different stenosis lengths in bell shape stenosis at $y=-0.5$

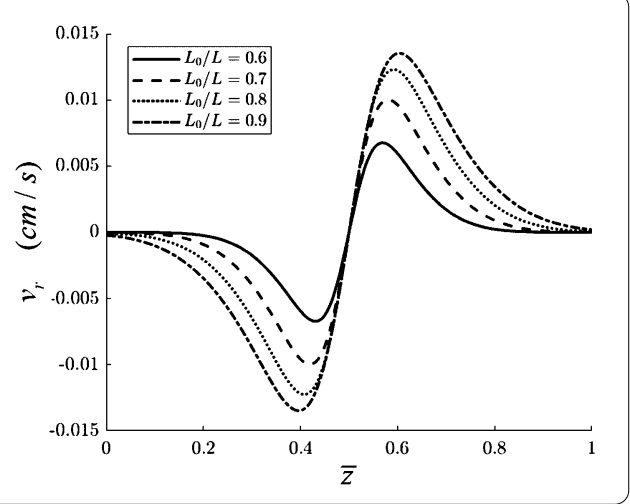

The results of resistance to the blood flow are shown in Figs. 28 to 30. The resistance to the flow of blood shows an upward trend that is contrary to the flow rate. The resistance to the flow is low when the stenosed height rises in the bell shape and combined shape of bell and cosine, but it has a high value in the cosine shape and combined shape of cosine and bell with the increasing stenosed height, which corresponds to Venkatsan and Sriyab's analysis $[9,10]$. Figure 30 indicates that the resistance to the flow in cosine shape displays the highest value. The flow rate and resistance to flow of the combined shapes are compared in Figs. 25 and 26, and Figs. 28 and 29. The flow rate and the resistance to the flow of blood in the combined shape shows the same behavior with the single shape when the geometry of stenosis is the same in the first half of the stenosis. While they are slightly different in a different geometry in the second half of the stenosis. 
Figure 19 Variation of radial velocity with radial distance for non-Newtonian ( $n=0.61$ and $n=0.828$ ) and Newtonian fluid $(n=1)$ in bell shape and combined shape of bell and cosine stenosis at $\bar{z}=0.8$

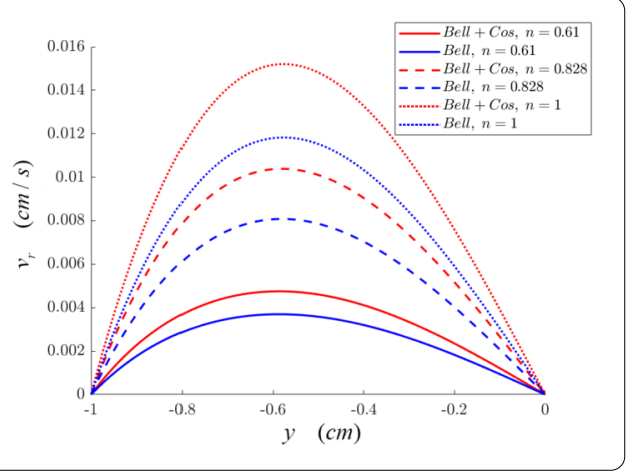

Figure $\mathbf{2 0}$ Variation of radial velocity with axial distance for non-Newtonian ( $n=0.61$ and $n=0.828$ ) and Newtonian fluid $(n=1)$ in bell shape and combined shape of bell and cosine stenosis at $y=-0.5$

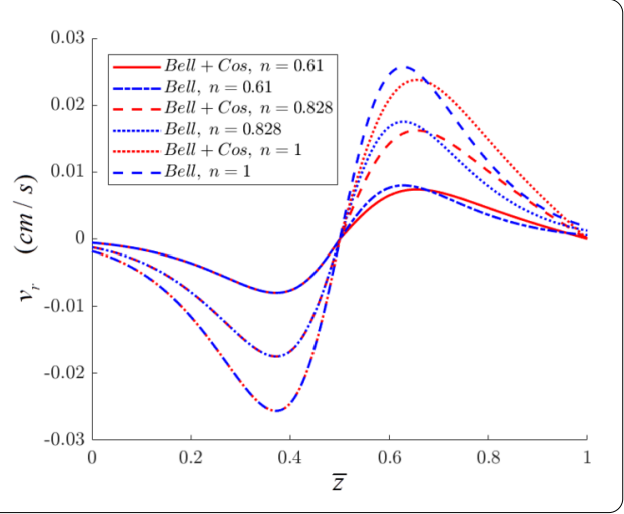

Figure 21 Variation of radial velocity with radial distance for non-Newtonian ( $n=0.61$ and $n=0.828$ ) and Newtonian fluid $(n=1)$ in cosine shape and combined shape of cosine and bell stenosis at $\bar{z}=0.8$

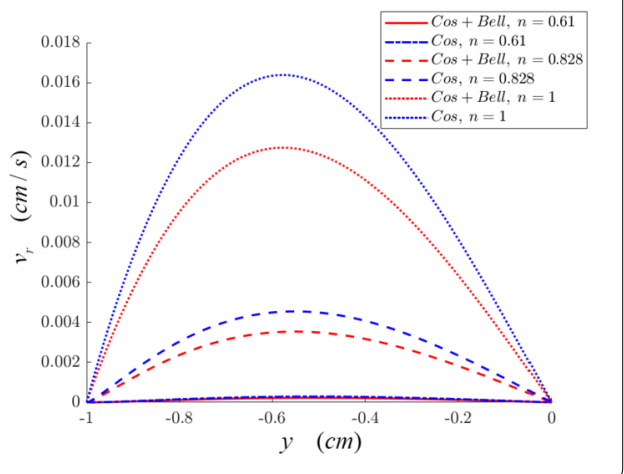

\subsection{Skin friction}

The behavior of skin friction $\left(\tau_{f}\right)$ that is shear stress at the surface of the stenosis artery has been studied in Figs. 31 to 35. The highest value of skin friction is located at the peak of the stenosis region and decreases in other regions, which is in accordance with J. Venkatsan, S. Sriyab, M.M. Molla, and S.P. Shupti. Figures 31 and 32 show that the value of skin friction increases when stenosis height increases. In Fig. 33, the skin friction increases with the increase of stenosis length, which qualitatively agrees with J. Venkatsan and S. Sriyab [9, 10]. The effect of non-Newtonian fluid is shown in Fig. 35. It is observed that skin friction increases considerably with the increase of $n$. The skin friction for a cosine shape stenosis artery exhibits a much lower value than the bell shape as seen in Fig. 34. However, the skin friction in the cosine shape is higher than the results of J. Venkatsan and S. Sriyab's study [9]. 
Figure 22 Variation of radial velocity with axial distance for non-Newtonian ( $n=0.61$ and $n=0.828$ ) and Newtonian fluid $(n=1)$ in cosine shape and combined shape of cosine and bell stenosis at $y=-0.5$

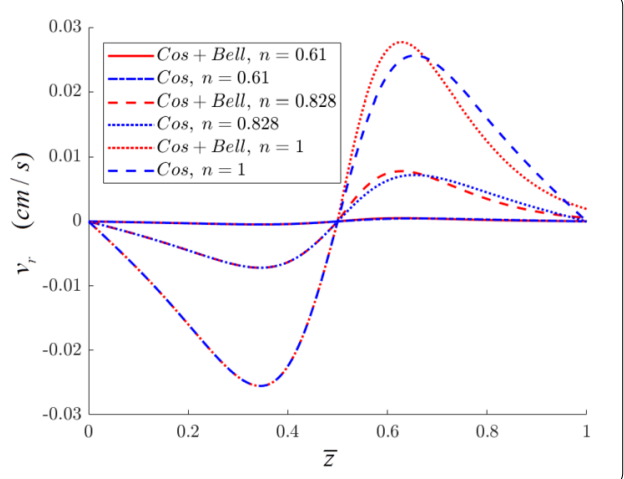

Figure $\mathbf{2 3}$ The comparison between the bell shape with different $m$ and cosine shape of radial velocity with radial distance at $\bar{z}=0.6$

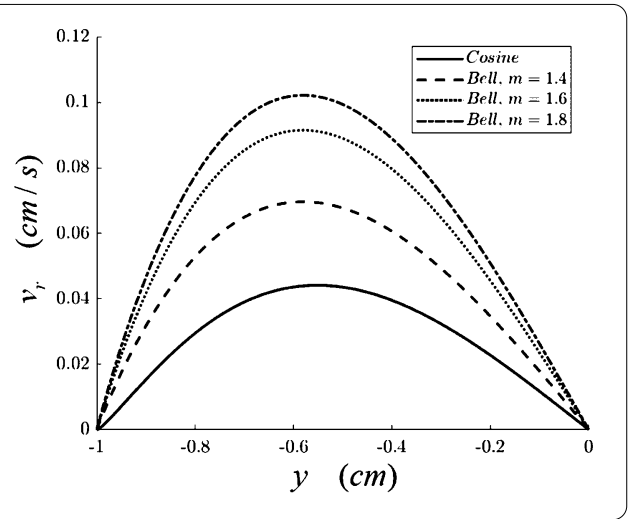

Figure $\mathbf{2 4}$ The comparison between the bell shape with different $m$ and cosine shape of radial velocity with axial distance at $y=-0.5$

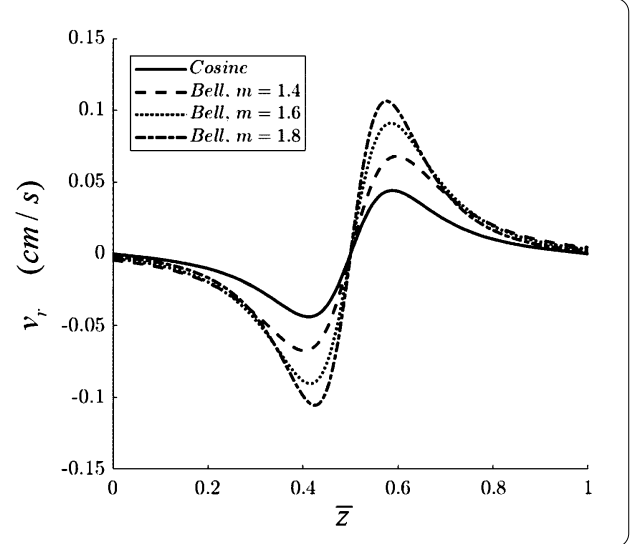

The effect of the combined shape on skin friction is shown in Figs. 31, 32, and 35. It shows similar results with the velocity and flow rate in that the skin friction in the combined shape has a different behavior from the skin friction in a single shape when $\bar{z}>0.5$.

\section{Conclusion}

In this study, we investigated the steady flow of the two-dimensional blood flow through the different stenosed arteries: the bell shape, cosine shape, and combined shape. The power-law model was used to represent the blood flow in non-Newtonian behavior. The flow quantities, which were axial velocity, radial velocity, flow rate, resistance to flow, and skin friction, were obtained by using the finite difference method. These results were com- 
Figure $\mathbf{2 5}$ Variation of flow rate with axial distance for different stenosis heights in bell shape and the combined shape of bell and cosine stenosis

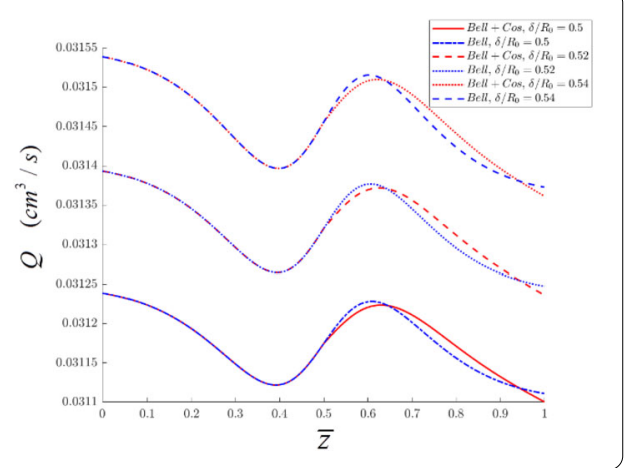

Figure 26 Variation of flow rate with axial distance for different stenosis heights in cosine shape and the combined shape of cosine and bell stenosis

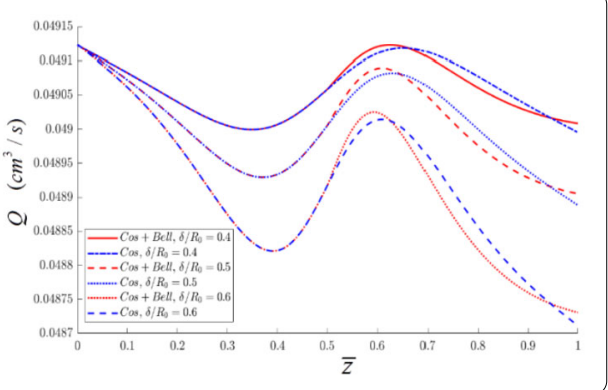

Figure $\mathbf{2 7}$ The flow rate comparison between the bell shape with different $m$ and cosine shape

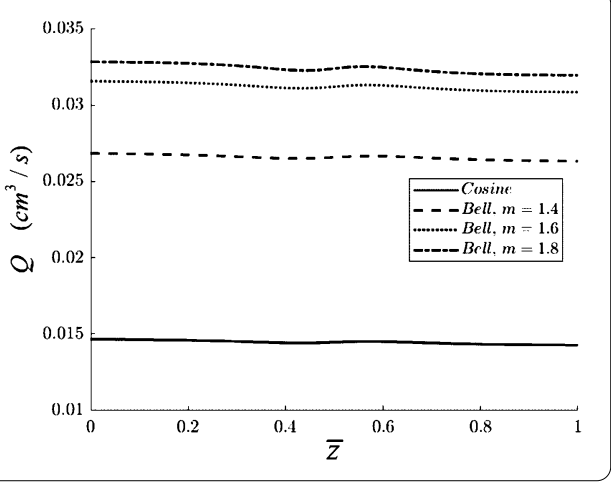

Figure 28 Variation of resistance to the flow with axial distance for different stenosis heights in bell shape and the combined shape of bell and cosine stenosis

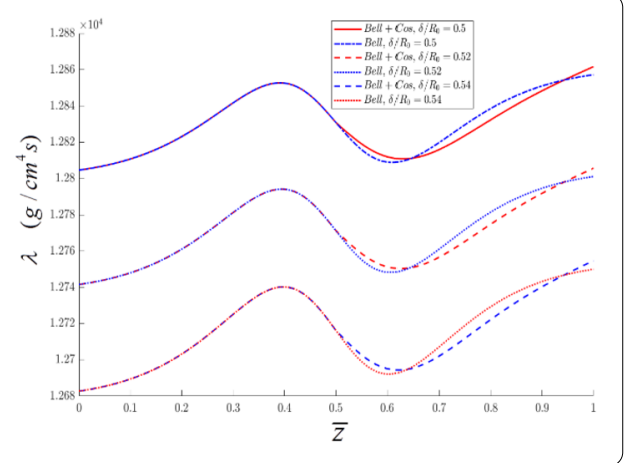

pared with the results of studies by Mandal [7], Venkatsan [9], Sriyab [10], Molla [15, 16], and Shupti [19]. The main results are as follows:

i. Axial velocity and radial velocity 
Figure 29 Variation of resistance to the flow with axial distance for different stenosis heights in cosine shape and the combined shape of cosine and bell stenosis

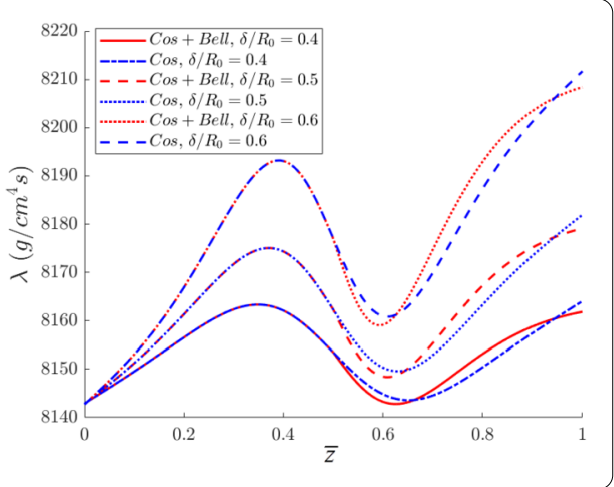

Figure $\mathbf{3 0}$ The resistance to the flow comparison between the bell shape with different $m$ and cosine shape

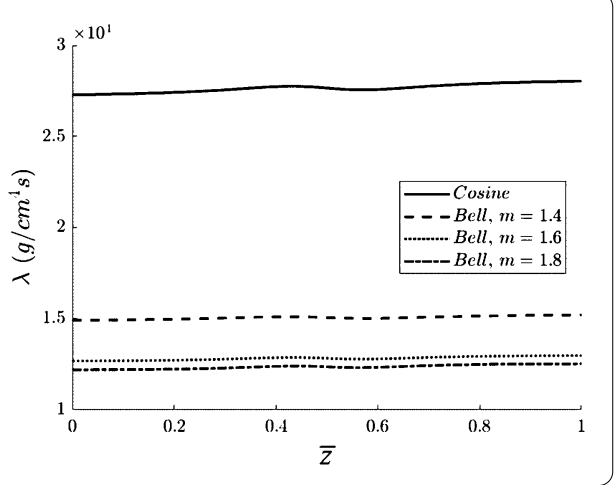

Figure 31 Variation of skin friction with axial distance for different stenosis heights in bell shape and combined shape of bell and cosine stenosis

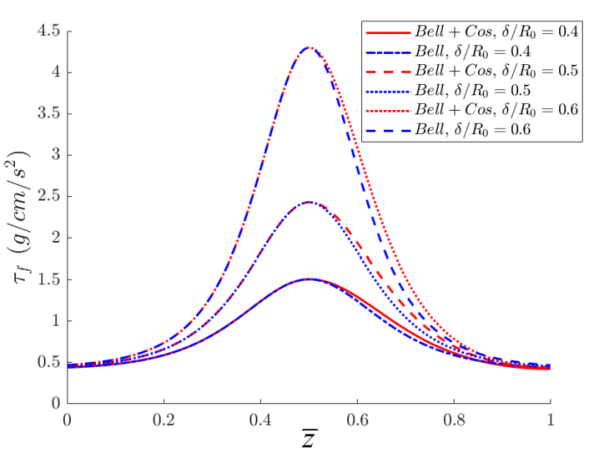

Axial velocity is the highest at the center of the stenosed artery which corresponds to the results of P.K. Mandal, M. M. Molla, and S. P. Shupti. Radial velocity shows a much lower value than axial velocity which is in accordance with P.K. Mandal also. Axial and radial velocity increase with the increase of stenosed height and stenosed length. The effect of non-Newtonian fluid shows that the velocity in axial and radial directions of Newtonian fluid is higher than the non-Newtonian fluid. Axial velocity and radial velocity in the cosine shape are much lower than in the bell shape. From the entrance of the stenosed region to the center of stenosed region, the single shape (bell shape or cosine shape) and combined shape display the same value of axial and radial velocity. However, from the center to the exit of the stenosed region, axial velocity in the single shape is slightly different from the combined shape.

ii. Flow rate and resistance to flow 
Figure 32 Variation of skin friction with axial distance for different stenosis heights in cosine shape and combined shape of cosine and bell stenosis

Figure 33 Variation of skin friction with axial distance for different stenosis lengths in bell shape stenosis
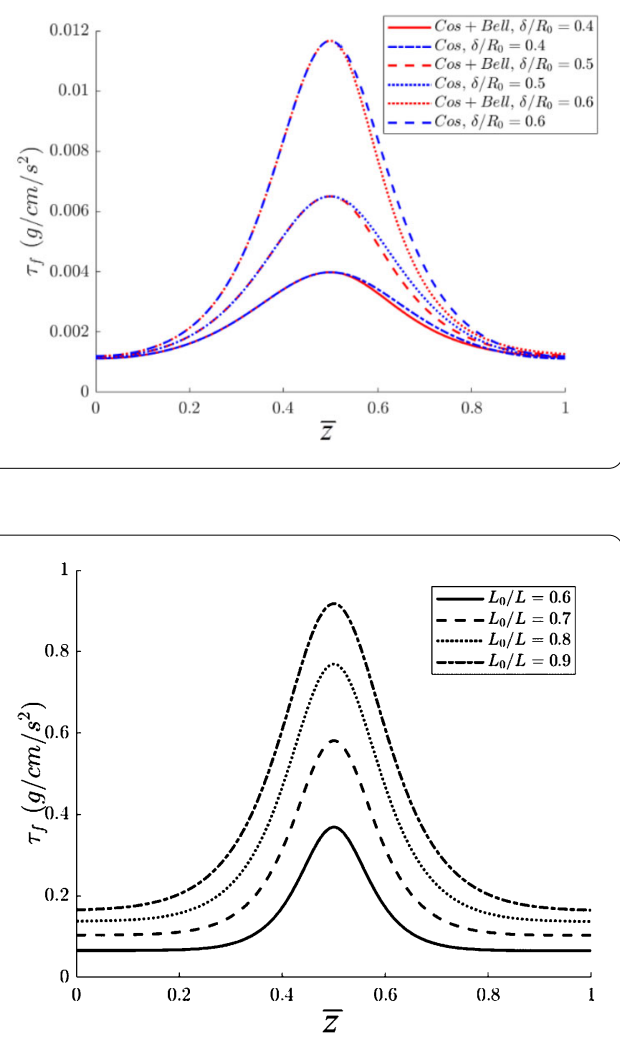

Figure 34 The skin friction comparison between bell shape with different $m$ and cosine shape

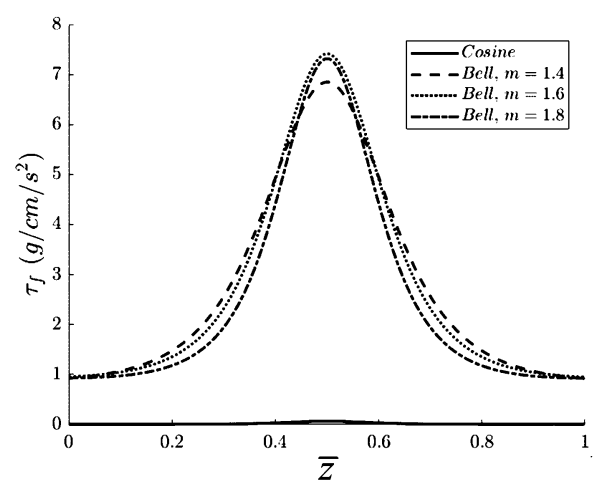

The flow rate behavior of our work and that of J. Venkatsan and S Sriyab's study with the same single shape are quite different phenomena because of the different non-Newtonian model. The resistance to the flow behavior contradicts the flow rate. The flow rate decreases with the increase of stenosis height in the bell shape and combined shape (bell shape and cosine shape), which is contrary to the results of J. Venkatsan and S. Sriyab. However, it increases with the increase of stenosis height in the cosine shape and combined shape (cosine shape and bell shape), which accords with the results of J. Venkatsan and S. Sriyab. The flow rate in the cosine shape is considerably lower than in the bell shape, while the resistance to the flow in the cosine shape is higher than in the bell shape. The resistance to flow in the combined shape is different from the single shape from the center to the exit of the stenosed region. 
Figure 35 Variation of skin friction with axial distance for non-Newtonian ( $n=0.61$ and $n=0.828$ ) and Newtonian fluid $(n=1)$ in bell shape and combined shape of bell and cosine stenosis

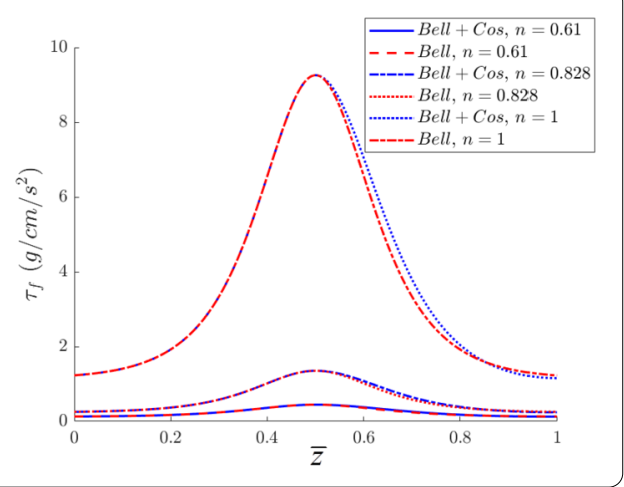

\section{iii. Skin friction}

The skin friction or the wall shear stress in power-law is lower than the Newtonian model but the skin friction in Cross model is higher than that in the Newtonian. The maximum shear stress occur near the center of the stenosis, which is in accordance with J. Venkatsan, S. Sriyab, and M. M. Molla. It increases with stenosis height and stenosis length, which is also in accordance with J. Venkatsan and S. Sriyab. The effect of nonNewtonian fluid indicates that skin friction in the Newtonian case shows a higher value than in the non-Newtonian case. The skin friction in the bell shape is much higher than in the cosine shape, which is contrary to J. Venkatsan and S. Sriyab. The effect of the combined shape on skin friction has a similar behavior as other flow quantities in which the skin friction in the combined shape and single shape displays the same behavior in the first half of stenosis, but the effect is slightly different in the last half of the stenosis.

The hemodynamics of blood flow in the arterial segment containing different stenosis geometry has been studied in presence of non-Newtonian effect. The non-Newtonian model is applied with the arterial segment whose radius is less than $1 \mathrm{~mm}$. Results show that the flow quantities are affected by stenosis geometry and non-Newtonian model. The flow quantities in different stenosis geometry indicates different blood flow behavior. It may help the doctor to diagnose the stenosis types in the patient who suffers from cardiovascular diseases. The arterial segment that is in vivo experiment, cosine or bell stenosis shapes, small radius (less than $1 \mathrm{~mm}$ ) is chosen to validate the simulation data. The interpolation of stenosis geometry and unsteady flow should be taken into consideration highlighting the scope of further work. The mechanical and biochemical aspects related to biofluid dynamics need adequate physiological value in the in vivo situation to understand the blood flow in biological and clinical facts [23].

Acknowledgements

This research work is supported by Chiang Mai University, Chiang Mai, Thailand.

Funding

Not applicable.

\section{Abbreviations}

$R(z)$, Radius of a stenosed artery (meters); $R_{0}$, Radius of a normal artery (meters); $\delta$, Highest depth of the stenosis (meters); $L_{1}$ Half length of an artery (meters); $L_{0}$, Half length of stenosis (meters); $v_{r}$, Radial velocity $(\mathrm{m} / \mathrm{s}) ; v_{z}$, Axial velocity $(\mathrm{m} / \mathrm{s}) ; \rho$, Density of the fluid $\left(\mathrm{kg} / \mathrm{m}^{3}\right) ; p$, Pressure of the fluid $\left(\mathrm{N} / \mathrm{m}^{2}\right) ; \tau_{r z}, \tau_{r r}$, Shear stress $\left(\mathrm{s}^{-1}\right) ; \tau_{z z}$, Normal stress $\left(s^{-1}\right) ; k$, Flow consistency index; $Q$, Volumetric flow rate $\left(\mathrm{m}^{3} / \mathrm{s}\right) ; \lambda$, The resistance to flow $(V / A)$. 


\section{Competing interests}

The authors declare that they have no competing interests.

\section{Authors' contributions}

All authors read and approved the final manuscript. All authors contributed equally to the writing of this paper.

\section{Authors' information}

Somchai Sriyab received his B.Sc. in Mathematics from Chiang Mai University, Thailand, in 2000. He then received his M.S and Ph.D. degrees from Mahidol University,Thailand, in 2003 and 2009, respectively. In 2005-2006, he went to do research with Prof. Li Shi Luo at Old Dominion University, USA. Dr. Somchai is currently an assistant professor at the Department of Mathematics at Chiang Mai University. His research interests include blood flow in arteries, mathematical modeling of fluid dynamics and mathematical modeling in biology and medicine. Pinyo Owasit received his B.Sc. in Food Process Engineering from Chiang Mai University, Thailand, in 2007. He graduated Master Degree of Applied Mathematics from Chiang Mai University 2019. His research interests include blood flow in arteries, mathematical modeling of fluid dynamics.

\section{Author details}

${ }^{1}$ M.Sc. Degree Program in Applied Mathematics, Department of Mathematics, Faculty of Science, Chiang Mai University, Chiang Mai, Thailand. '2Department of Mathematics, Faculty of Science, Chiang Mai University, Chiang Mai, Thailand. ${ }^{3}$ Research Center in Mathematics and Applied Mathematics, Department of Mathematics, Faculty of Science, Chiang Mai University, 50200, Chiang Mai, Thailand.

\section{Publisher's Note}

Springer Nature remains neutral with regard to jurisdictional claims in published maps and institutional affiliations.

Received: 18 May 2020 Accepted: 1 July 2021 Published online: 16 July 2021

\section{References}

1. Mustapha, N., Mandal, P.K., Johnson, P.R., Amin, N.: A Numerical Simulation of Unsteady Blood Flow Though Multi-Irregular Arterial Stenoses. Appl. Math. Model. 34, 1559-1573 (2010)

2. Chakravarty, S., Mandal, P.K.: Two-dimensional blood flow through tapered arteries under stenotic conditions. Int. J. Non-Linear Mech. 35, 779-793 (2000)

3. Gauthier, P.: Mathematics in Atmospheric Sciences: An Overview. In: Discrete Geometry for Computer Imagery, 22-23 (2009)

4. Ismail, Z., Abdullah, I., Mustapha, N., Amin, N.: A Power-law Model of Blood Flow Through a Tapered Overlapping Stenosed Artery. Appl. Math. Comput. 195, 669-680 (2008)

5. Prakash, J., Ogulu, A.: A study of pulsatile blood flow modeled as a power law fluid in a constricted tube. Int. Commun. Heat Mass Transf. 34, 762-768 (2007)

6. Nadeem, S., Akbar, N.S., Hendi, A.A., Hayat, T.: Power law Fluid Model for Blood Flow Through a Tapered Artery with a Stenosis. Appl. Math. Comput. 217, 7108-7116 (2011)

7. Mandal, P.K.: An unsteady analysis of non-Newtonian blood flow through tapered arteried with a stenosis. Int. J. Non-Linear Mech. 40, 151-164 (2005)

8. Siddiqui, S., Verma, N., Mishra, S., Gupta, R.: Mathematical modelling of pulsatile flow of Casson's fluid in arterial stenosis. Appl. Math. Comput. 210, 1-10 (2009)

9. Venkatesan, J., Sankar, D., Hemalatha, K., Yatim, Y.: Mathematical Analysis of Casson Fluid Model for Blood Rheology in Stenosed Narrow Arteries. J. Appl. Math. (2013)

10. Sriyab, S.: Mathematical analysis of non-Newtonian blood flow in stenosis narrow arteries. Comput. Math. Methods Med. (2014)

11. Misra, J., Shit, G.: Blood flow through arteries in a pathological state: a theoretical study. Int. J. Eng. Sci. 44(10), 662-671 (2006)

12. Easthope, P., Brooks, D.: A comparison of rheological constitutive functions for whole human blood. Biorheology 17, 235-247 (1980)

13. Nadeem, S., Kaini, M.N., Saleem, A., Issakhove, A.: Microvascular Blood Flow with Heat Transfer in a Wavy Channel having Electroosmotic Effects. Electrophoresis 21, 1198-1205 (2020)

14. Tan, Y.B., Mustapha, N.: Gravitational influences on micropolar blood flow in a bifurcated artery with mild stenosis. Int. J. Adv. Appl. Sci. 5(11), 24-32 (2018)

15. Tan, Y.B., Mustapha, N.: The Gravitational Effects of Blood Flow in Irregular Stenosed Artery with Various Severity. J. Math. Comput. Sci. 2(2), 28-39 (2016)

16. Jeong, W.W., Rhee, K.: Effects of surface geometry and non-Newtonian viscosity on the flow field in arterial stenoses. J. Mech. Sci. Technol. 23, 2424-2433 (2009)

17. Bird, R.B., Stewart, W.E., Lightfoot, E.N.: Transport Phenomena. Madison, USA (1960)

18. Robertson, A.M., Sequeira, A., Owens, R.G.: Cardiovascular Mathematics. Springer, Berlin (2009)

19. Molla, M.M., Hossain, A., Wang, B-C., Kuhn, D.C.S.: Large eddy simulation of pulsatile non-Newtonian flow based on dynamics nonlinear subgrid stress model. Prog. Comput. Fluid Dyn. 12(4), 231-242 (2012)

20. Molla, M.M., Paul, M.C.: LES of non-Newtonian physiological blood flow in a model of arterial stenosis. Med. Eng. Phys. 34, 1079-1087 (2012)

21. Shupti, S.P., Rabby, M.G., Molla, M.M.: Rheological Behavior of Physiological Pulsatile Flow through a Model of Arterial Stenosis with Moving Wall. J. Fluids (2015)

22. Malota, Z., Glowacki, J., Sadowski, W., Kostur, M.: Numerical analysis of the impact of flow rate, heart rate, vessel geometry, and degree of stenosis on coronary hemodynamic indices. BMC Cardiovasc. Disord. 18, 132 (2018)

23. Carvalho, V., Pinho, D., Lima, R.A., Teixeira, J.C., Teixeira, S.: Blood Flow Modeling in Coronary Arteries: A Review. Fluids 6, 53 (2021) 